\title{
Relationship between Stress and Bone Density, Using Salivary Cortisol, in Young Adult Women
}

\author{
Fumihiro Omasu1, Satomi Ohhira1, Mikiko Satoh1, Mizuki Kawai1, Sena Nagasaki1, \\ Kosuke Hiruma ${ }^{2}$
}

${ }^{1}$ Department of Health and Nutrition, Faculty of Health and Nutrition, Yamagata Prefectural Yonezawa University of Nutrition Sciences, Yonezawa-Shi, Yamagata, Japan

${ }^{2}$ Faculty of Social Information Science, Yamagata Prefectural Yonezawa Woman's Junior College, Yonezawa-Shi, Yamagata, Japan Email: omasu@yone.ac.jp

How to cite this paper: Omasu, F., Ohhira S., Satoh, M., Kawai, M., Nagasaki, S. and Hiruma, K. (2020) Relationship between Stress and Bone Density, Using Salivary Cortisol, in Young Adult Women. Open Journal of Preventive Medicine, 10, 1-8. https://doi.org/10.4236/ojpm.2020.101001

Received: January 3, 2020

Accepted: January 28, 2020

Published: January 31, 2020

Copyright (C) 2020 by author(s) and Scientific Research Publishing Inc. This work is licensed under the Creative Commons Attribution International License (CC BY 4.0).

http://creativecommons.org/licenses/by/4.0/

\begin{abstract}
Although cortisol is believed to increase the osteoclast activity and accentuate bone resorption, few studies are available on cortisol and bone density. This study uses salivary cortisol to investigate the relationship thereof with bone density. Furthermore, we investigated whether the salivary Ca concentration could be an effective biomarker in bone evaluations using salivary cortisol. This study targeted 188 healthy female college students (18 - 25 years old). Calcaneus bone density (Speed of Sound: SOS) was measured using an ultrasonic bone density measurement device. Food intake was calculated via a food intake frequency survey. The saliva of subjects was collected in order to measure the cortisol concentration using an enzyme immunoassay, while the salivary $\mathrm{Ca}$ concentration was measured using an atomic absorption spectrophotometer. The relationship between salivary cortisol and SOS was not significant, with a correlation coefficient of -0.13 , indicating a negative correlation and leading to the observation that those with lower salivary cortisol levels tended to have higher SOS. The relationship between salivary cortisol and salivary Ca concentration was not significant, with a correlation coefficient of +0.15 , indicating a positive correlation and leading to the observation that those with higher salivary cortisol concentrations tended to have higher salivary $\mathrm{Ca}$ concentrations. No significant correlation was observed in the relationship between salivary Ca concentration and SOS. Because the cortisol in saliva responds more sensitively to acute stress than to chronic stress, this may not have had obvious significance. Furthermore, the salivary $\mathrm{Ca}$ concentration indicated large fluctuations, depending on the daily external conditions, particularly in terms of food; therefore, it is believed that the presence or absence of dietary intake before the survey affected the results. The above results suggest that bone density may decrease, while salivary $\mathrm{Ca}$ concentration may increase when salivary cortisol concentration increases due to stress.
\end{abstract}




\section{Keywords}

Bone Density, Food Intake Frequency, Salivary Cortisol, Calcium

Concentration

\section{Introduction}

In recent years, it has been reported that stress-related factors impair health [1]. A recent study reported that those with high daily stress had a higher incidence of cerebrovascular disease and ischemic heart disease [2]. Given these trends, non-invasive salivary cortisol is garnering attention as a physiological evaluation method for stress [1]. Salivary cortisol is a type of steroid hormone released from the adrenal cortex. When stress is placed on the human body, the hormones released from the hypothalamus act on the pituitary gland, causing adrenocorticotropic hormone to be secreted from the pituitary gland and leading to the secretion of cortisol by acting on the adrenal cortex. This cortisol is a type of glucocorticoid that promotes bone resorption and suppresses bone formation. Osteoporosis may be caused by Cushing's syndrome, due to excessive secretion of cortisol or long-term administration of steroids [3].

Further, it is believed that complications of secondary hyperparathyroidism may occur if steroid hormones, including glucocorticoids and cortisol, cause a decrease in calcium (hereinafter, abbreviated as $\mathrm{Ca}$ ) absorption in the intestinal tract, leading to the occurrence of a negative Ca balance in the kidney [4] [5]. In doing so, it is assumed that parathyroid hormone, which increases blood Ca concentration, is over-secreted and bone resorption through osteoclasts increases, while blood Ca concentration rises.

There are few studies on cortisol and bone density. This study uses salivary cortisol to investigate whether stress affects bone density loss. We also investigate whether salivary $\mathrm{Ca}$ concentration is an effective biomarker in bone evaluations using salivary cortisol.

\section{Materials and Methods}

The subjects were 188 healthy female college students, aged 18 to 25 , who had been attending university for 0.5 to 2.5 years. All data in the present study were collected in July 2019 at the college in the middle area of Tohoku. Each of the subjects lived in the area surrounding the college. Females with a history of treatment or therapy that might have influenced bone mass were excluded. The study was approved by the Ethics Committee of Epidemiological Studies at Yamagata Prefectural Yonezawa University of Nutrition Sciences.

Their bone density was measured using an ultrasonic bone density measuring device (Canon Lifecare Solutions Co., Ltd., CM-200) in order to measure the ultrasonic propagation speed (speed of sound; hereinafter abbreviated as SOS) of the right calcaneus, which was set as an index of density. 
After distributing a food intake frequency questionnaire (Kenpakusha, Excel Nutrition 2015, food intake frequency survey FFQg Ver.5.0) to all subjects, they were asked to fill out the form so that the daily intake for each nutrient and food group could be calculated using computer software.

Saliva was collected from the subjects and the salivary cortisol concentration was measured by an enzyme immunoassay using a kit (Salimetrics, Salivary EIA Kit) for quantifying cortisol contained in the saliva samples. The calcium concentration was measured using an atomic absorption spectrophotometer (SHIMADZU, AA-7000).

The physical characteristics of the subjects were expressed as a mean and standard deviation. Correlation coefficients with SOS were obtained with respect to age, height, weight, BMI, salivary cortisol concentration, and salivary calcium concentration. The correlation coefficient between the average daily intake of nutrients and SOS was determined based on the dietary intake status survey. The correlation coefficient was determined between salivary cortisol and SOS, between salivary cortisol and salivary calcium, and between salivary calcium and SOS, respectively. All correlation coefficients were tested with a level of significance of $5 \%$.

\section{Results}

The results of the physical characteristics of the subjects are shown in Table 1 as a mean and standard deviation. The height, weight and BMI of the subjects evaluated in this study were within the normal range based on the national average of Japanese adult females. The average salivary cortisol concentration and calcium concentration were $0.3 \pm 0.4 \mu \mathrm{g} / \mathrm{dL}$ and $15.8 \pm 5.8 \mathrm{mg} / \mathrm{dL}$, respectively. With respect to the values, although the salivary calcium concentration was slightly high, the results were standard [6].

The correlation coefficients between age, height, weight, BMI, and SOS, respectively, were determined and shown in Table 1. Although the correlation coefficients between age, height, weight, BMI, and SOS, respectively, did not indicate a significant trend, there was a negative correlation with age and height as well as a positive correlation with weight and BMI.

Table 1. Physical characteristics of the subjects.

\begin{tabular}{ccc}
\hline & $\begin{array}{c}\text { Mean } \pm \text { standard } \\
\text { deviation }\end{array}$ & $\begin{array}{c}\text { Correlation coefficient } \\
\text { with SOS }\end{array}$ \\
\hline Age (years old) & $19.2 \pm 1.0$ & -0.048 \\
Height $(\mathrm{cm})$ & $156.0 \pm 20.6$ & -0.027 \\
Weight $(\mathrm{kg})$ & $51.7 \pm 9.5$ & 0.099 \\
BMI $\left(\mathrm{kg} / \mathrm{cm}^{2}\right)$ & $20.5 \pm 3.5$ & 0.115 \\
SOS $(\mathrm{m} / \mathrm{sec})$ & $1517.7 \pm 29.9$ & - \\
Salivary cortisol concentration $(\mu \mathrm{g} / \mathrm{dL})$ & $0.3 \pm 0.4$ & -0.128 \\
Salivary calcium concentration $(\mathrm{mg} / \mathrm{dL})$ & $15.8 \pm 5.8$ & -0.007 \\
\hline
\end{tabular}


With respect to the nutrients that affect SOS, the average daily intake by the subjects and the daily intake standard values for women aged 18 to 29 , based on the "Japanese dietary intake standards" (2015 version) [7]), are shown in Table 2.

Regarding energy, the physical activity level was set to II (normal) and the estimated energy requirement was shown. With respect to proteins, lipids, and carbohydrates, target amounts were expressed as energy ratios of total energy intake. Recommended amounts were indicated for calcium, magnesium, and iron, while adequate amounts were indicated for phosphorus, vitamin $\mathrm{D}$, and vitamin $\mathrm{K}$, with target amounts indicated for equivalent salt amounts. Furthermore, the correlation coefficient between the average daily nutrient intake by the subjects and SOS was determined and shown in Table 2. Although the correlation coefficient was not significant, vitamin $\mathrm{K}$ was negatively correlated and other nutrients were positively correlated.

Although the calculated correlation coefficient between salivary cortisol concentration and SOS was -0.13 , which was not significant, a negative correlation was observed.

Although the calculated coefficient between the salivary cortisol concentration and salivary calcium concentration was +0.15 , which was not significant, a positive correlation was observed.

The calculated correlation coefficient between salivary calcium concentration and SOS was -0.007 , which was not a significant correlation.

Table 2. Nutrients and SOS.

\begin{tabular}{|c|c|c|c|}
\hline & Standard value & $\begin{array}{l}\text { Average intake } \\
\text { by subjects }\end{array}$ & $\begin{array}{c}\text { Correlation } \\
\text { coefficient with SOS }\end{array}$ \\
\hline Energy (kcal/day) & 1950 & 1584.10 & 0.033 \\
\hline Protein (\%) & $13-20$ & $13.7(54.18 \mathrm{~g})$ & 0.043 \\
\hline Lipid (\%) & $20-30$ & $31(54.67 \mathrm{~g})$ & 0.028 \\
\hline Carbohydrate (\%) & $50-65$ & $53.6(212.09 \mathrm{~g})$ & 0.024 \\
\hline Calcium (mg/day) & 650 & 440.42 & 0.009 \\
\hline Magnesium (mg/day) & 270 & 193.90 & 0.027 \\
\hline Phosphorus (mg/day) & 800 & 807.69 & 0.046 \\
\hline Iron (mg/day) & 10.5 & 5.69 & 0.016 \\
\hline Vitamin D ( $\mu$ /day) & 5.5 & 3.36 & 0.099 \\
\hline Vitamin $\mathrm{K}(\mu /$ day $)$ & 150 & 176.36 & -0.014 \\
\hline Salt equivalent (g/less than a day) & 7.0 & 7.68 & 0.076 \\
\hline
\end{tabular}




\section{Discussion}

Based on the results, there was no correlation between each nutrient and SOS. There are reports suggesting that there is no relationship between nutrients and SOS [8] [9]. In a longitudinal study using the DXA method (dual-energy X-ray absorptiometry) for 15 years from the age of 13 to 28 , body weight change, rather than calcium intake, during the observation period, indicated a stronger relation to bone mass change [8]. There is also a report indicating that a study using quantitative ultrasound measurement methods to compare changes in indices, including when skipping meals, excess consumption of instant foods, smoking and drinking behavior, etc., which seem to reflect lifestyle disturbances, found no association and only finding a statistically significant difference in the item "exercise habits." [9]. Furthermore, it has been suggested that the intake frequency of dairy products, such as milk and cheese, is strongly related to changes in bone mass [10]. However, some reports have concluded that dairy products increase bone mass only in boys, with no significant effect in girls [11].

Therefore, it is difficult to say whether or not the frequency of intake of each nutrient directly affects SOS. There is potentially a gender difference in terms of the effects of dairy product intake on bone mass increase or bone loss suppression in young adulthood, so the relationship between dairy products and bone density is an issue that needs to be investigated going forward.

Although those with lower salivary cortisol concentrations tended to have higher SOS, no significant correlation was observed. As a reason for this, it was the first to point out that cortisol responds more sensitively to acute stress than to chronic stress. It was speculated that the stress caused by the unusual situation of collecting saliva might have caused changes in the cortisol level of subjects. However, cortisol is known to temporarily increase in short-term stress situations, such as mental arithmetic calculations and oral presentations [12] [13], in addition to also being known to increase in daily and chronic stress situations, such as unemployment or divorce [14] [15] [16]. Therefore, the robustness of salivary cortisol as a stress evaluation index and a unified understanding of the characteristics thereof have not been established as of yet, making it necessary to carefully examine whether it is appropriate as an evaluation index.

Secondly, cortisol has a secretory rhythm that is high in the morning and low at night. Cortisol increases from $50 \%$ to $60 \%$ from 30 to 45 minutes after waking up [17]. Because the value is affected by whether 8:00 in the morning is right after getting up or 2 hours after getting up, etc., it was necessary to check the wake-up time as well when the study is designed to collect saliva at a fixed time such as in this study. Because the saliva collection time of subjects was divided into two groups, at approximately 10:00 a.m. and 1 p.m., it is possible that the saliva collection time affected the results.

Thirdly, the estrous cycle may affect salivary substance concentrations when targeting women [18]. Some studies have conducted investigations during the period from the late luteal phase to the early follicular phase, when female hor- 
mone secretion is low [19], making it necessary to take measures such as controlling the timing of the estrous cycle during saliva collection.

Although it was observed those with higher salivary cortisol concentrations had higher salivary Ca concentrations, there was no significant correlation. As a reason for such a result, the first issue to be pointed out is the abovementioned external influences on salivary cortisol, wherein it is assumed saliva Ca also being an index, which is similarly susceptible to external influences, is somehow related. Therefore, it was necessary to take measures such as calling on the subjects to abstain from eating food before collecting saliva.

The second point is that the mixed salivary Ca concentration fluctuates drastically. The saliva collected in this study was mixed saliva, secreted from all parotid, submandibular, and sublingual glands. However, the mixed salivary $\mathrm{Ca}$ concentration is particularly susceptible to food, as described above, particularly in the oral cavity. Therefore, going forward, it is necessary to consider a method for collecting saliva that takes into account the variability of mixed saliva and conduct further detailed research.

The probable reason for there being no significant relationship between salivary Ca concentration and SOS was, as described above, that the saliva Ca concentration could not be measured accurately due to the saliva Ca concentration being easily affected by external factors such as meals. Similarly, more precise results may be obtained by setting conditions such as not allowing the subjects to eat before saliva collection.

\section{Conclusions}

In this study, 188 female college students were targeted, among which we observed and examined, in a cross-sectional manner, the nutrient intake, etc. that affects SOS changes, salivary cortisol concentration as a stress index, and salivary Ca concentration that is assumed to affect the salivary cortisol concentration.

No significant relationship was found between salivary cortisol levels, which are assumed to be stress evaluation indicators and SOS. Although the relationship between salivary cortisol concentration and salivary Ca concentration was examined, because steroid hormones are factors that increase blood $\mathrm{Ca}$ concentration (that is, promote bone resorption), no significant relationship was observed.

These results did not reveal that cortisol, believed to be secreted due to stress, reduces bone density. Furthermore, salivary Ca concentration might not be an index to evaluate bone density.

However, no studies have yet conducted an observational longitudinal investigation prospectively on Japanese female college students in order to explore factors affecting bone density. In this study, as a pioneer to discover factors affecting bone density, learning from failures such as the inappropriate method of collecting saliva, we would like to establish an evaluation method that can obtain more precise results and contribute to the prevention of illness in healthy individuals in the working environment of an advanced information society. 


\section{Conflicts of Interest}

The authors declare no conflicts of interest regarding the publication of this paper.

\section{References}

[1] Izawa, S., Shirotsuki, K., Sugaya, N., Ogawa, N., Suzuki, K. and Nomura, S. (2007) The Application of Saliva to an Assessment of Stress: Procedures for Collecting and Analyzing Saliva and Characteristics of Salivary Substances. The Japanese Society for Complementary and Alternative Medicine, 4, 91-101. (In Japanese) https://doi.org/10.1625/jcam.4.91

[2] Iso, H., Date, C., Yamamoto, A., Toyoshima, H., Tanabe, N., Kikuchi, S., Kondo, T., Watanabe, Y., Wada, Y., Ishibashi, T., Suzuki, H., Koizumi, A., Inaba, Y., Tamakosh, A. and Ohno, Y. (2002) Perceived Mental Stress and Mortality from Cardiovascular Disease among Japanese Men and Women: The Japan Collaborative Cohort Study for Evaluation of Cancer Risk Sponsored by Monbusyho (JACC Study). Circulation, 106, 1229-1236. https://doi.org/10.1161/01.CIR.0000028145.58654.41

[3] Kaneko, K. and Kawai, S. (2011) Mechanisms and Therapeutics of GlucocorticoidInduced Osteoporosis. The Japan Society for Clinical Immunology, 34, 138-148. (In Japanese) https://doi.org/10.2177/jsci.34.138

[4] Paz-Pacheco, E., Fuleihan, G.E. and LeBoff, M.S. (1995) Intact Parathyroid Hormone Levels Are Not Elevated in Glucocorticoid-Treated Subjects. Journal of Bone and Mineral Research, 10, 1713-1718. https://doi.org/10.1002/jbmr.5650101114

[5] Pearce, G., Tabensky, D.A., Delmas, P.D., Baker, H.W. and Seeman, E. (1998) Corticosteroid-Induced Bone Loss in Men. The Journal of Clinical Endocrinology \& Metabolism, 83, 801-806. https://doi.org/10.1210/jcem.83.3.4621

[6] Sato, N. (1959) Variation of Calcium Concentration in the Human Saliva. Journal of Dental Health, 9, 63-73. (In Japanese)

[7] Ministry of Health, Labor and Welfare (2015) Outline of Japanese Dietary Intake Standards (2015 Version).

[8] Welten, D.C., Kemper, H.C., Post, G.B., Van Mechelen, W., Twisk, J., Lips, P. and Teule, G.J. (1994) Weight Bearing Activity during Youth Is a More Important Factor for Peak Bone Mass than Calcium Intake. Journal of Bone and Mineral Research, 9, 1089-1096. https://doi.org/10.1002/jbmr.5650090717

[9] Omasu, F., Umemoto, M., Gotanda, R. and Gotoh, T. (2017) Effect that Lifestyle during the Growth Period Has on Bone Density Acquisition-Using Simple Exercise and a Nutrition Survey. Open Journal of Preventive Medicine, 7, 87-97. https://doi.org/10.4236/ojpm.2017.75008

[10] Sakamoto, H. and Miyoshi, M. (2000) Factors Affecting the Stiffness Index and Its Annual Change in Female Students - Relationship with Menu Choice and Exercise Duration. The Japanese Journal of Nutrition and Dietetics, 58, 5-14. (In Japanese) https://doi.org/10.5264/eiyogakuzashi.58.5

[11] Ibuka, E., Ohida, T., Miyake, T., Suzuki, K., Motojima, S., Harano, S., Yokoyama, E., Kaneita, Y., Kaneko, A. and Takeda, F. (2004) Relationships between Finding of Calcaneal Quantitative Ultrasound and Lifestyle in Japanese College Students. Japanese Journal of Public Health, 51, 764-773. (In Japanese)

[12] Kirschbaum, C. and Hellhammer, D.H. (1994) Salivary Cortisol in Psychoneuroendocrine Research: Recent Developments and Applications. Psychoneuroendocrinology, 19, 313-333. https://doi.org/10.1016/0306-4530(94)90013-2 
[13] Dickerson, S.S. and Kemeny, M.E. (2004) Acute Stressors and Cortisol Responses: A Theoretical Integration and Synthesis of Laboratory Research. Psychological Bulletin, 130, 355-391. https://doi.org/10.1037/0033-2909.130.3.355

[14] Steptoe, A., Cropley, M., Griffith, J. and Kirschbaum, C. (2000) Job Strain and Anger Expression Predict Early Morning Elevations in Salivary Cortisol. Psychosomatic Medicine, 62, 286-292. https://doi.org/10.1097/00006842-200003000-00022

[15] Ockenfels, M.C., Porter, L., Smyth, J., Kirschbaum, C., Hellhammer, D.H. and Stone, A.A. (1995) Effect of Chronic Stress Associated with Unemployment on Salivary Cortisol: Overall Cortisol Levels, Diurnal Rhythm, and Acute Stress Reactivity. Psychosomatic Medicine, 57, 460-467. https://doi.org/10.1097/00006842-199509000-00008

[16] Powell, L.H., Lovallo, W.R., Matthews, K.A., Meyer, P., Midgley, A.R., Baum, A., Stone, A.A., Underwood, Lynn., McCann, J.J., Herro, K.J. and Ory, M.G. (2002) Physiologic Markers of Chronic Stress in Premenopausal, Middle-Aged Women. Psychosomatic Medicine, 64, 502-509. https://doi.org/10.1097/00006842-200205000-00015

[17] Pruessner, J.C., Wolf, O.T., Hellhammer, D.H., Buske-Kirschbaum, A., von Auer, K., Jobst, S., Kaspers, F. and Kirschbaum, C. (1997) Free Cortisol Levels after Awakening: A Reliable Biological Marker for the Assessment of Adrenocortical Activity. Life Sciences, 61, 2539-2549. https://doi.org/10.1016/S0024-3205(97)01008-4

[18] Kirschbaum, C., Kudielka, B.M., Gaab, J., Schommer, N.C. and Hellhammer, D.H. (1999) Impact of Gender, Menstrual Cycle Phase, and Oral Contraceptives on the Activity of the Hypothalamus-Pituitary-Adrenal Axis. Psychosomatic Medicine, 61, 154-162. https://doi.org/10.1097/00006842-199903000-00006

[19] Isowa, T., Ohira, H. and Murashima, S. (2004) Reactivity of Immune, Endocrine and Cardiovascular Parameters to Active and Passive Acute Stress. Biological Psychology, 65, 101-120. https://doi.org/10.1016/S0301-0511(03)00115-7 